\title{
Arthroscopic Management of Intra-articular Ligament Lesions on Distal Radius Fractures
}

\section{Manejo artroscópico de lesiones de ligamentos intraarticulares en fracturas del radio distal}

\author{
Marcio Aurelio Aita ${ }^{1}$ Ricardo Kaempf ${ }^{2}$ Re $^{\circledR}$ Bruno Gianordoli Biondi ${ }^{1}$ Gary Alan Montano $^{1}$ \\ Fernando Towata ${ }^{1}$ Gustavo Luis Gomez Rodriguez ${ }^{30}$ Gustavo Mantovani Ruggiero ${ }^{4}$
}

1 Faculdade de Medicina do ABC, Santo André, São Paulo, SP, Brazil

${ }^{2}$ Santa Casa de Misericórdia, Porto Alegre, RS, Brazil

${ }^{3}$ Hospital Britanico de Buenos Aires, Argentina

${ }^{4}$ Università Degli Studi Di Milano, Orthopaedics Department, Milano, MI, Italy

Rev Iberam Cir Mano 2021;49:24-36.
Address for correspondence Marcio Aurelio Aita, PhD, Faculdade de Medicina do ABC, Santo André, São Paulo, SP, Brazil (e-mail: marcioaita@me.com).

\author{
Abstract

\section{Keywords} \\ - distal radius fracture \\ - treatment-oriented \\ classification \\ - ligament lesion
}

Articular distal radius fractures (DRFs) have increased in incidence in recent years, especially among the economically active population. Most of the treatment approaches are based on plain X- rays, and do not give us any information on how to treat these fractures. In the search for solutions with greater precision in diagnosis, in reducing the joint surface of the fracture, and envolving minimally-invasive techniques, we found arthroscopy as the main tool for these patients. Therefore, an enhanced understanding of the biomechanics of the different types of fracture associated with ligamentous lesions should facilitate the right decision regarding the treatment. The present paper aims at providing a managementoriented concept to diagnose and treat ligamentous lesions associated with intra-articular DRFs based on a arthroscopy-assisted procedure, and showing the objective and patientreported outcomes and a new classification. The objective and patient-reported outcomes were: the mean range of motion (ROM) was of $94.80 \%$ on the non-affected side; the mean score on the abbreviated version of the Disabilities of the Arm, Shoulder and Hand questionnaire (QuickDASH) was of 3.6 (range: 1 to 12). The score on the Visual Analog Scale (VAS) was of 1.66 (range: 1 to 3). Complications were observed in 2 (13.33\%) patients: extensor tendon synovitis in 1 patient, and a limitation (stiffness) in ROM in 1 patient, both treated with wrist arthroscopy release. The mean time until the return to work was of 6.4 weeks. In patients with unstable intra-articular DRFs associated with ligamentous lesions, the fixation of specific osseous-ligamentous fragments and ligamentous repair/reconstruction by wrist arthroscopy prove to be a safe and reliable treatment. The clinical and functional results predict that the patients can return to work more quickly. received

August 19, 2020

accepted

February 4, 2021
DOI https://doi.org/ $10.1055 / \mathrm{s}-0041-1730393$ ISSN 1698-8396.

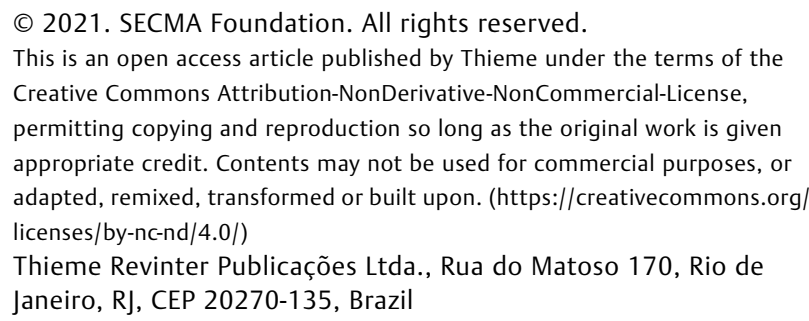




\section{Resumen}

\section{Palabras clave}

- fractura de radio distal

- clasificación orientada al tratamiento

- lesión de ligamento
Las fracturas articulares del radio distal han aumentado su incidencia en los últimos años, especialmente en la población económicamente activa. La mayoría de las veces el tratamiento se basa en radiografías simples y no nos dan ninguna información sobre cómo tratar estas fracturas. En la búsqueda por soluciones con mayor precisión en el diagnóstico, en la reducción de la superficie articular de la fractura, y con técnicas mínimamente invasivas, encontramos la artroscopia como la principal herramienta para estos pacientes. Por lo tanto, una mejor comprensión biomecánica de los diferentes tipos de fracturas asociadas a las lesiones de ligamentos debería facilitar la decisión correcta de tratamiento. Este artículo tiene como objetivo proporcionar un concepto orientado al tratamiento para el manejo de las lesiones ligamentarias asociadas a las fracturas intraarticulares del radio distal basado en un procedimiento asistido por artroscopia, y mostrar los resultados objetivos y reportados por el paciente y una nueva clasificación. Los resultados objetivos y reportados por el paciente fueron: el rango de movimiento (RDM) medio fue de $94,80 \%$ del lado no afectado; la puntuación media en la versión abreviada del cuestionario de Discapacidades del Brazo, Hombro y Mano (Disabilities of the Arm, Shoulder and Hand, QuickDASH, en inglés) fue de 3,6 (rango: 1 a 12). La puntuación en la Escala Visual Analógica (EVA) fue de 1,66 (rango: 1 a 3). Hubo complicaciones en 2 (13,33\%) pacientes: una sinovitis del tendón extensor en 1 paciente, y limitación del RDM (rigidez) en 1 paciente, ambos tratados con liberación artroscópica de muñeca. La media de tiempo hasta el regreso al trabajo fue de 6,4 semanas. En pacientes con fracturas intraarticulares inestables del radio distal asociadas a lesiones de ligamentos, la fijación de fragmentos óseoligamentosos específicos y la reparación/reconstrucción de ligamentos mediante artroscopia de muñeca demuestran ser un tratamiento seguro y fiable. Los resultados clínicos y funcionales predicen que los pacientes pueden volver a trabajar más pronto.

\section{Introduction}

The incidence of articular distal radius fractures (DRFs) has increased recently, especially among the economically-active population. The frequency of surgery for patients with DRF has also increased. Arthroscopy is considered the primary tool available for these patients, as it utilizes minimally-invasive techniques, reduces the joint surface of the fracture, and enables a higher precision in diagnosis. Arthroscopic techniques enable surgeons to perform surgery for DRFs via a direct and anatomical reduction of the joint surface, with sufficient stability for early mobility of the joint, preserving the proprioception and the vascularization of the tissues, often resulting in the patients resuming their regular personal or professional activities. Arthroscopy of the wrist requires specific characteristics and tools that generally follow these basic principles: creation of work or vision portals, identification of the lesion, and a specific treatment procedure; the standard of conduct for the postoperative care of these patients is very similar to that of procedures in other joints. Imaging scans of upper-limb joint fractures have been used for the initial diagnosis for many years. In recent years, plain radiography is often the first test to be ordered; however, the computed tomography (CT) scan has gained momentum, and is particularly useful to measure deviations and to check bone consolidation. ${ }^{1,2}$ Furthermore, magnetic resonance imaging (MRI) is useful to diagnose occult fractures $^{3}$ and associated ligament injuries; however, it is not superior to arthroscopy, so it is not widely used. Articular fractures appear differently, depending on the pattern and the associated trauma mechanism. Thus, torsional and indirect traumas present avulsion fracture patterns, and traumas in which the upper limb is used for protection (to support the body load, for example) are considered direct fractures by compression. ${ }^{4}$ Arthroscopically-assisted techniques have broadened the technique spectrum, particularly when reducing intra-articular fractures and in the diagnosis of ligamentar lesions. Therefore, understanding the enhanced biomechanics of the different fracture types associated with ligament lesions should help facilitate an accurate treatment protocol. ${ }^{5}$ Conservative treatment is an acceptable option for ligament injuries, fractures without deviation, and stable fractures, as it poses fewer risks and enables earlier mobilization by keeping the radiocarpal joint congruent. Another important factor is the time elapsed between the injury and the start of treatment. As with all injuries, prompt treatment generally results in a better prognosis. ${ }^{6}$ The present study sought to provide a management-oriented concept for the diagnosis and treatment of ligament lesions associated with the stabilization of intraarticular DRFs based on a arthroscopy-assisted procedure through the presentation of objective and patient-reported outcomes (range of motion [ROM], Quick Disabilities of the Arm, Shoulder and Hand [QuickDASH] questionnaire, Visual Analog Scale [VAS], grip strength. and time until return to work) for classification. 


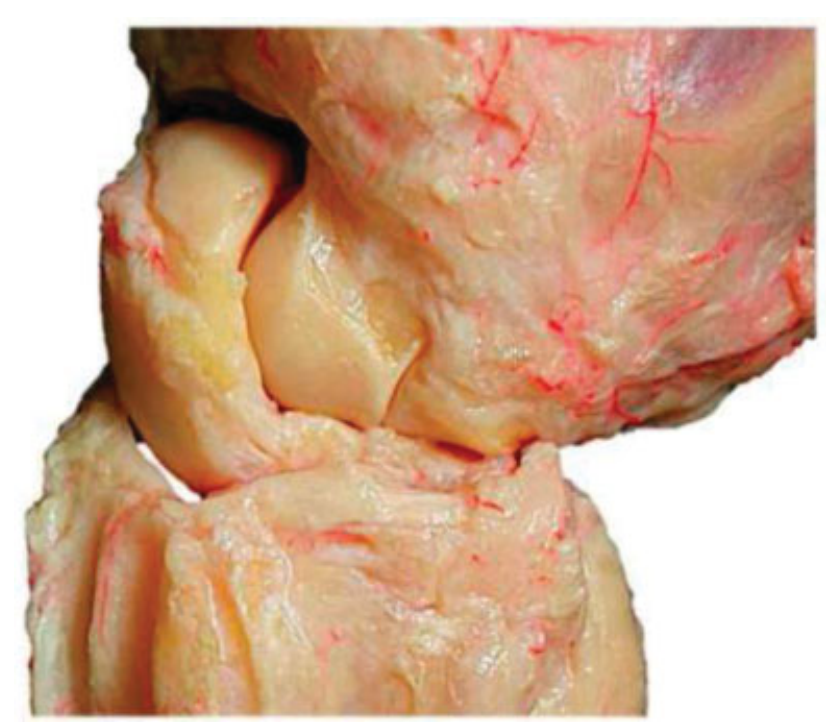

Fig. 1 Perfect relationship between the radiocarpal bone and the ligaments.

\section{Principles of Biomechanics}

The biomechanics of the wrist involves both kinetic (performing the movement) and cinematic (bearing load) motion. The basic prerequisites for regular motion of the carpus are (-Fig. 1):

(1) Intact bone stock of the radius and ulna.

(2) Intact intrinsic ligaments conjoin the proximal carpal row to a variable geometrical condyle versus the invariable proximal and distal counterparts.

(3) Intact extrinsic ligaments coordinate the proximal row with the radius and ulna against the distal carpal row, which acts as a monolith. ${ }^{7}$

(4) The role of proprioception and neuromuscular control in carpal stability.

The rather strong palmar ligaments support the proximal row like a cummerbund and act against forces of the dorsal side like a tension band (-Fig. 2 ) $^{8}$

The basic factors that cause DRF include the acting forces, the position of the wrist, and the resistance of the ligaments. Specific fracture types arise from the interaction among these parameters. These ligaments appear to reinforce the bone at their origin. Fracture patterns in two-part fractures generally occur in the area between the ligamentous zones. Intra-articular fractures show six different patterns, and at least one corner remains intact with the shaft. From a biomechanical standpoint, these bone-ligament fragments form a unit and tend to dislocate in different directions depending on their ligamentous attachment sites. ${ }^{9-11}$ (-Fig. 3). Recent laboratory research has revealed that carpal ligaments exhibited different kinetic behaviors depending on the direction and point of application of the forces to the wrist. The helical antipronation ligaments were usually active when the wrist was axially loaded; whereas the helical antisupination ligaments constrained the supination torques to the

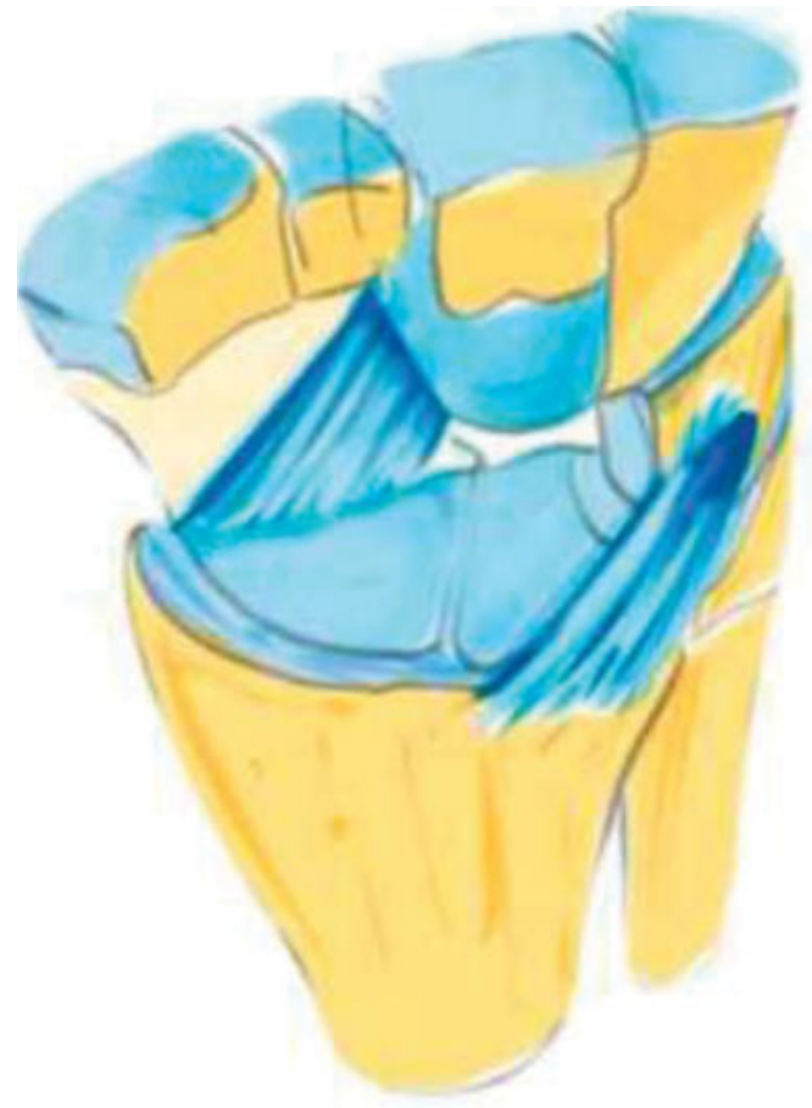

Fig. 2 The dorsal v-ligaments are on the dorsal aspect of the wrist, and the two proximal and distal $v$-ligaments are situated on the palmar aspect of the wrist, and they keep the carpus in position.

distal row. This novel way of interpreting the function of the carpal ligaments might assist in developing improved strategies for the treatment of carpal instabilities (-Fig. 4). ${ }^{12}$

In the past decade, a fourth factor in carpal stability has been proposed, which involves the neuromuscular and proprioceptive control of the joints (-Fig.5). The proprioception of the wrist originates from afferent signals, and is elicited by sensory end organs (mechanoreceptors) in the ligaments and joint capsules. It elicits spinal reflexes for immediate joint stability, and a higher order of neuromuscular influx to the cerebellum and sensorimotor cortices for planning and executing joint control. ${ }^{11,12}$

\section{Clinical Relevance}

However, many of these injuries have a mixed or complex trauma mechanism, as well as other ligament injuries not observed on the X-ray exam. The clinical relevance of the present article lies in the identification of occult lesions (perilunate injuries, not displaced, PLINDs) ${ }^{13}$ associated with distal radius fractures, in which the fixation of the bone-ligament fragments is not sufficient to maintain the stabilization of the wrist joint, and in the proposal of a new classification and appropriate and specific treatment for these injuries. 


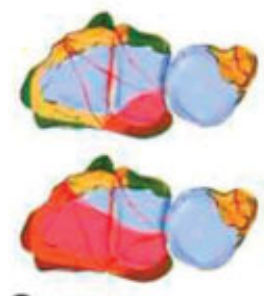

a

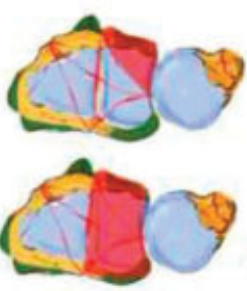

Cos

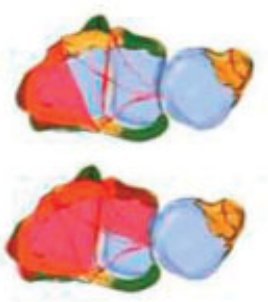

b

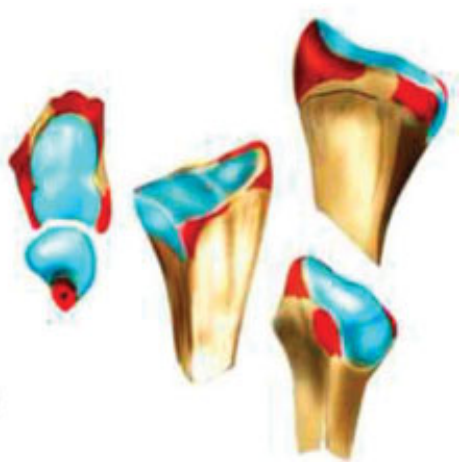

Fig. 3 In partial intra-articular fractures, six different patterns can be observed. At least one corner remains intact and in continuity with the shaft (A). The origins of the extrinsic ligaments are shown, which seem to reinforce the bone (B). ${ }^{6}$

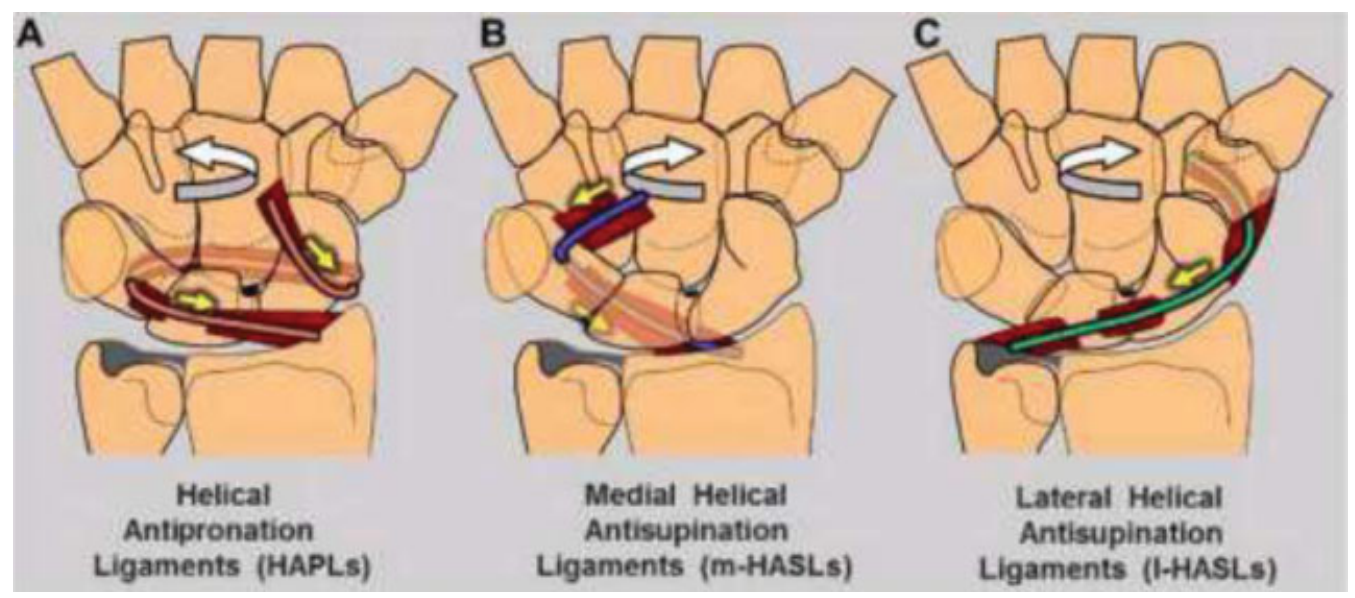

Fig. 4 Three groups of ligaments play a specific role in the primary stabilization of the axially-loaded carpus. (A) The helical antipronation ligaments become simultaneously taut (yellow arrows) when the distal row is torqued in pronation (curved white arrow). (B) The medial helical antisupination ligaments (HASLs) resist (yellow arrows) the tendency of the ulnar-side bones to translocate palmarly (curved white arrow). (C) The lateral HASLs become particularly active (yellow straight arrow) when the distal row is forced into supination (curved white arrow). ${ }^{12}$

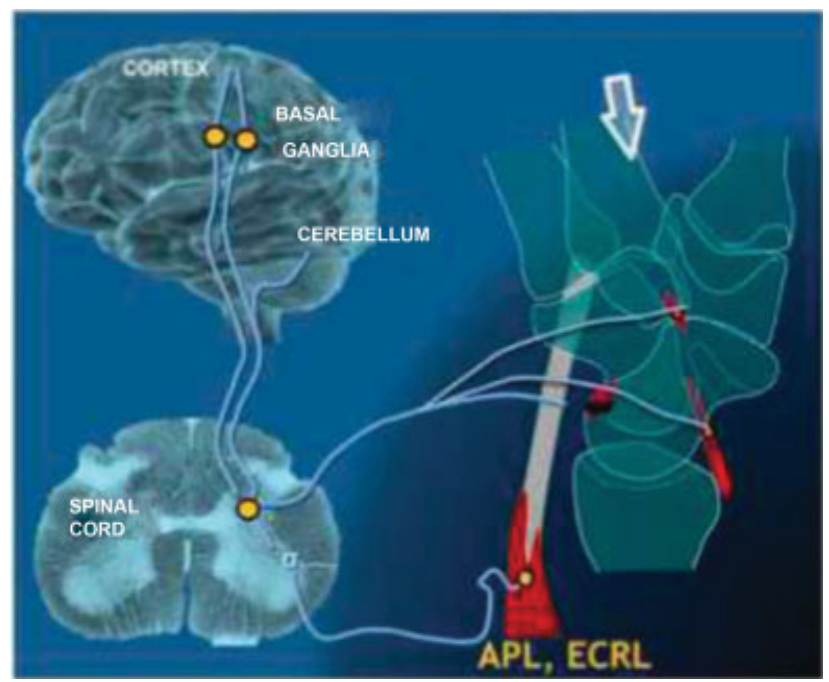

Fig. 5 Schematic design to understand the proprioception of the wrist - neuromuscular control. APL, abductor pollicis longus; ECRL, extensor carpi radialis longus.

\section{Methods}

In total, 150 patients with articular DRFs were selected as subjects in the present study, which was conducted at Centro Hospitalar Municipal de Santo André (CHMSA), in the city of Santo André, Brazil. The patients were diagnosed, treated, and subjected to clinical follow-up (-Figs. 6 and 7). The surgical procedures used included ${ }^{1}$ temporary fixation of the joint fragments with Kirschner wires, or procedures associated with a volar or dorsal plate under fluoroscopic control; ${ }^{2}$ arthroscopic fine adjustment of the reduction (we mainly use radiocarpal portals 3-4 and 6-R); ${ }^{3}$ rigid fixation of the joint fragments with screws, under arthroscopic guidance; ${ }^{4}$ and exploration of the radiocarpal, scapholunate, lunotriquetral ligament complex, and of the triangular fibrocartilage complex (radio carpal portals 3-4, 6-R, and central volar). ${ }^{14}$ Following the arthroscopic identification of the lesions, we started with the stabilization of the radius fracture:

1) rigid fixation with the volar locking plates (extraarticular fragments); ${ }^{15}$ 2) arthroscopic control of the joint reduction. 


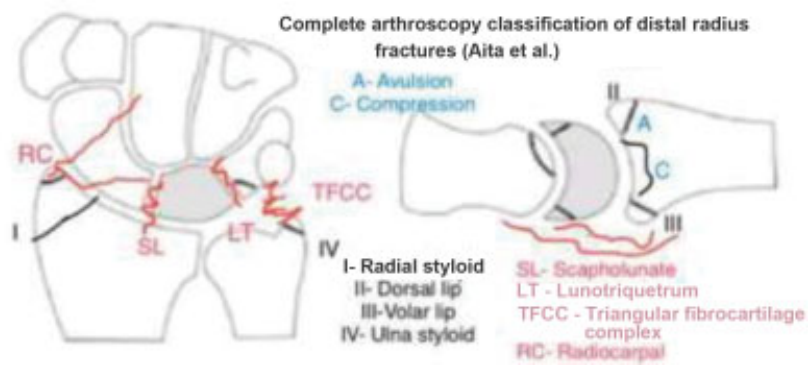

Fig. 6 Complete arthroscopy classification of distal radius fractures (Aita et al.).

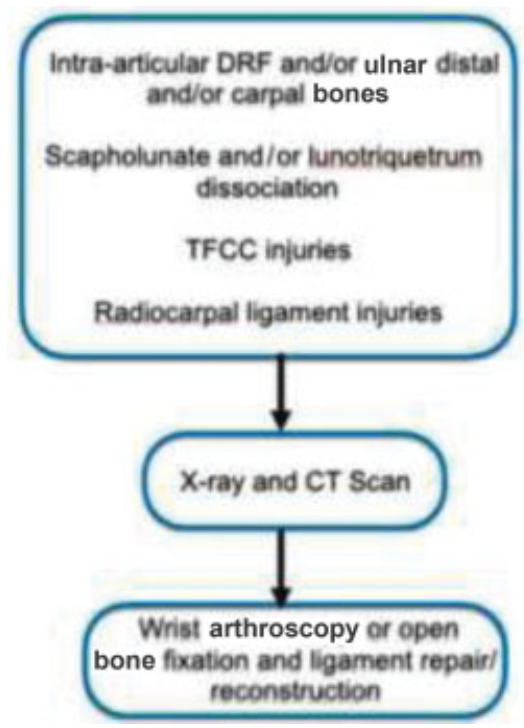

Fig. 7 Algorithm for the steps of the treatment for distal radius fractures (Aita et al.).

In avulsion-fractures (bone ligament fragments), cannulated headless compression screws (HCSs) and Kirschner wires, or specific fragment-type hook plates, were used ( - Fig. 8). Compression-type fractures (-Figs. 9,10,11) cannulated HCSs, Kirschner wires, blocked intramedullary nail (Micronail, Wright Medical Memphis, TN, US), or a graft (autologous or synthetic) were used to fill the bone gap that appeared following fracture reduction.
The ideal approach and type of implant: regarding the large number of implants available on the market, it is important to consider which type would be the most suitable to stabilize a specific fracture type, with regard to economic considerations, and not every fracture type necessarily requires the most expensive treatment. ${ }^{5}$

The first step was to determine the correct approach and use it to assess the subsequent measures necessary to prevent secondary dislocation of the carpus (to check ligament lesions associated the bone-ligament fragments). This seems to be more important than a perfect reduction. Specific fragments of the plates did not compromise the flexor tendons; however, they offered only limited possibilities to grasp and stabilize the very distal fracture elements. For the treatment of single fragments, cannulated self-tapping screws are becoming increasingly popular, and the minimally-invasive arthroscopy-assisted methods, in our opinion, were state-of-art, with the plate or nail or screw as the best solution.

3) Approach to associated ligament injuries

a) Reparable:

- thermal shrinkage ${ }^{16}$ or thermal shortening (by radiofrequency) of the ligament fibers;

- direct suture ${ }^{17}$ (with or without anchors; InternalBrace, Arthrex, Inc., Naples, FL, US) (-Figs. 12,13, and 14);

- indirect suture ${ }^{18}$ (with or without anchors; InternalBrace $)(-$ Fig. 15 and - Video $\mathbf{1})$;

- reinsertion ${ }^{19}$ (with or without anchors / InternalBrace) - Fig. 16);

- dorsal or palmar capsulodesis ${ }^{20,21}$ (with or without anchors; InternalBrace) (-Figs. 17,18, and - Video 1).

b) Irreparable:

- arthroscopic debridement of the joint extension (removing scar or pulvinar fibrosis) ${ }^{22}$

(-Video 2);

- reconstruction: graft, bone tunnels, augmenta$\operatorname{tion}^{23-26}$ (- Fig. 10 and - Videos 3,4);

- transarticular stabilization if necessary.
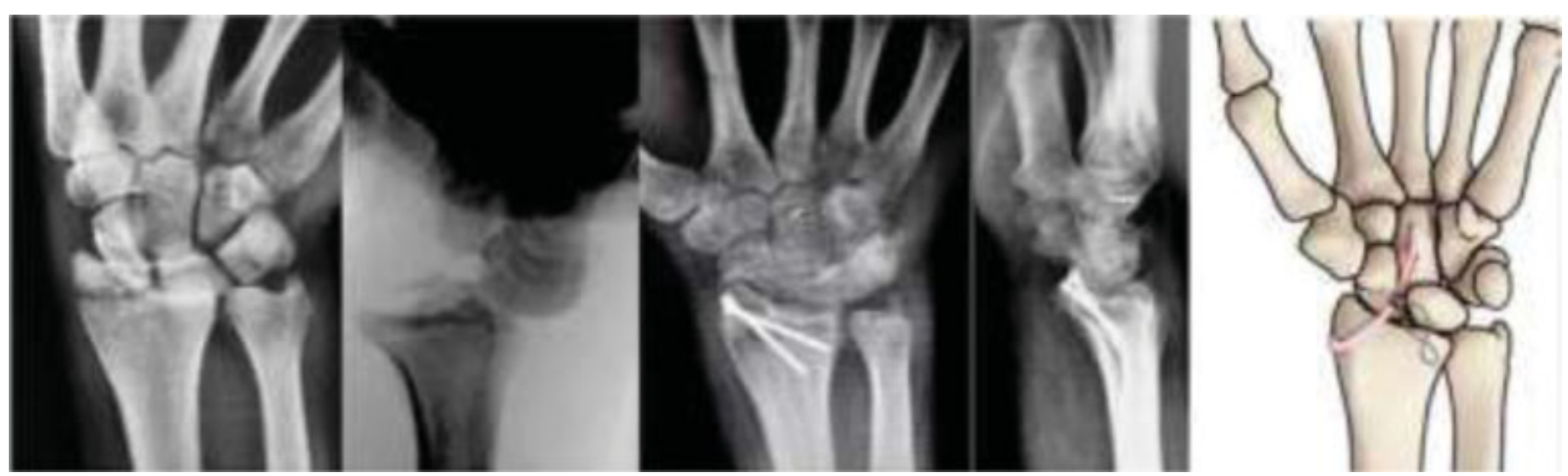

Fig. 8 Pre- and postoperative radiographic aspects: fracture-dislocation radiocarpal-avulsion of the radial styloid process by the radioscaphocapitate (RSC) ligament - surgical treatment with headless compression screw (HCS, Synthes, Solothurn, Switzerland) and reconstruction of the RSC ligament ${ }^{11 \mathrm{~A}}$ with InternalBrace and mini pushlock anchor (Arthrex, Inc., Naples, FL, US), assisted by arthroscopy. 


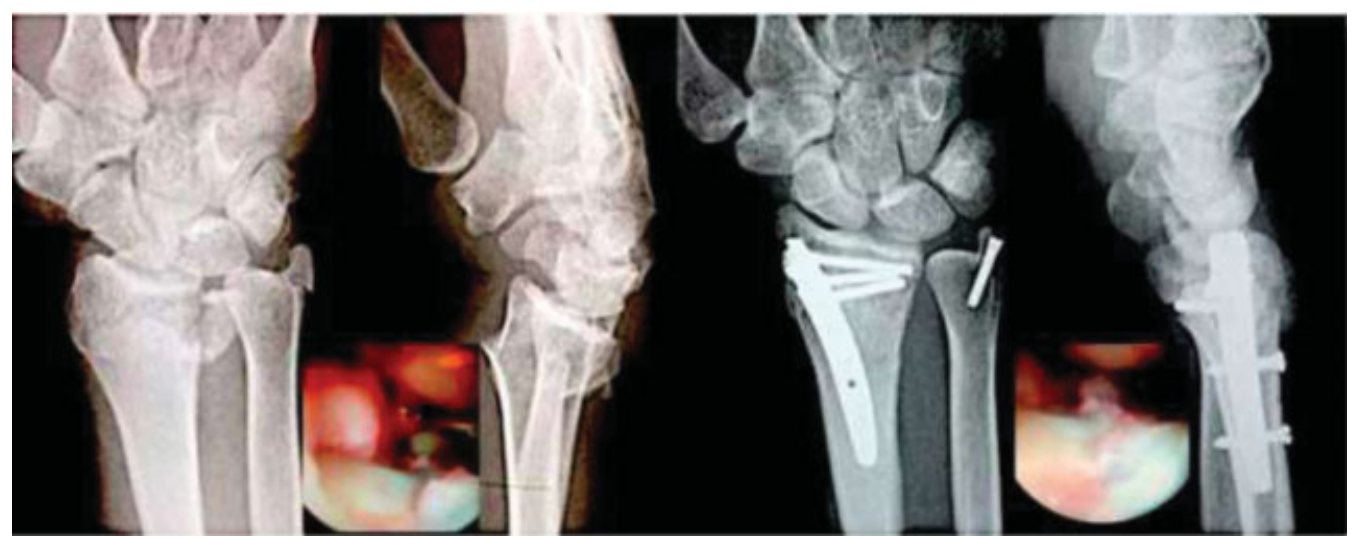

Fig. 9 Pre- and postoperative radiographic aspects: articular compression fracture of the distal end of the radius and avulsion styloid process of the ulna by the triangular fibrocartilage (TFC) ligament - surgical treatment with intramedullary nail Micronail (Wright Medical Technology, Orlando, FL, US) and Micro Acutrak (Acumed, Hillsboro, OR, US) compression screw.

\section{Video 1}

Schematic procedure for SLL indirect repair (InternalBrace): scapholunate axis method ${ }^{19}$ and procedure by Mathoulin et al. ${ }^{21}$ (dorsal capsulo-scapholunate septum capsulodesis) - entire arthroscopy procedure.

Online content including video sequences viewable at: https://www.thieme-connect.com/products/ejournals/ html/10.1055/s-0041-1730393.

\section{Video 2}

Intraoperative wrist arthroscopy (portal 3-4): arthroscopic debridement of the joint extension (removing scar/“pulvinar" fibrosis - scapholunate ligament chronic lesion).

Online content including video sequences viewable at: https://www.thieme-connect.com/products/ejournals/ html/10.1055/s-0041-1730393.

\section{Video 3}

Schematic procedure for irreparable lesion to the distal interosseous membrane: ligament reconstruction with brachiorradialis tendon graft.

Online content including video sequences viewable at: https://www.thieme-connect.com/products/ ejournals/html/10.1055/s-0041-1730393.

\section{Video 4}

Schematic procedure for SLL irreparable lesion: $360^{\circ}$ $\mathrm{SL}+$ dorsal capsulodesis reconstruction - the entire arthroscopy procedure.

Online content including video sequences viewable at: https://www.thieme-connect.com/products/ejournals/ html/10.1055/s-0041-1730393.

\section{Postoperative Period}

The rehabilitation protocol included the use of static orthosis in the first two weeks, with exercises of proprioception and the "dart throw movie" for the wrist, elbow flexion, and fingers since the first day after surgery. ${ }^{27}$ Active kinesiotherapy exercises and dynamic orthoses, assisted by physiotherapy or occupational therapy professionals, were used from the third week onwards. The retrn to work or sports activities was faster than with the conventional surgical approach. This assessment must be individualized, associated with trauma, applied as a surgical technique, and dependent on the profession or sportsrelated function of each patient. The study participants were encouraged to perform activities that avoided overload or changes in function.

\section{Results}

The idea of improving the diagnosis with the inclusion of arthroscopy in the treatment of these injuries also establishes a greater precision in the choice of the treatment method, and that is how we obtained the results herein described.

The objective and patient-reported outcomes are shown in - Table 1. The mean ROM was of $94.80 \%$ on the nonaffected side. The mean score on the QuickDASH was of 3.6 

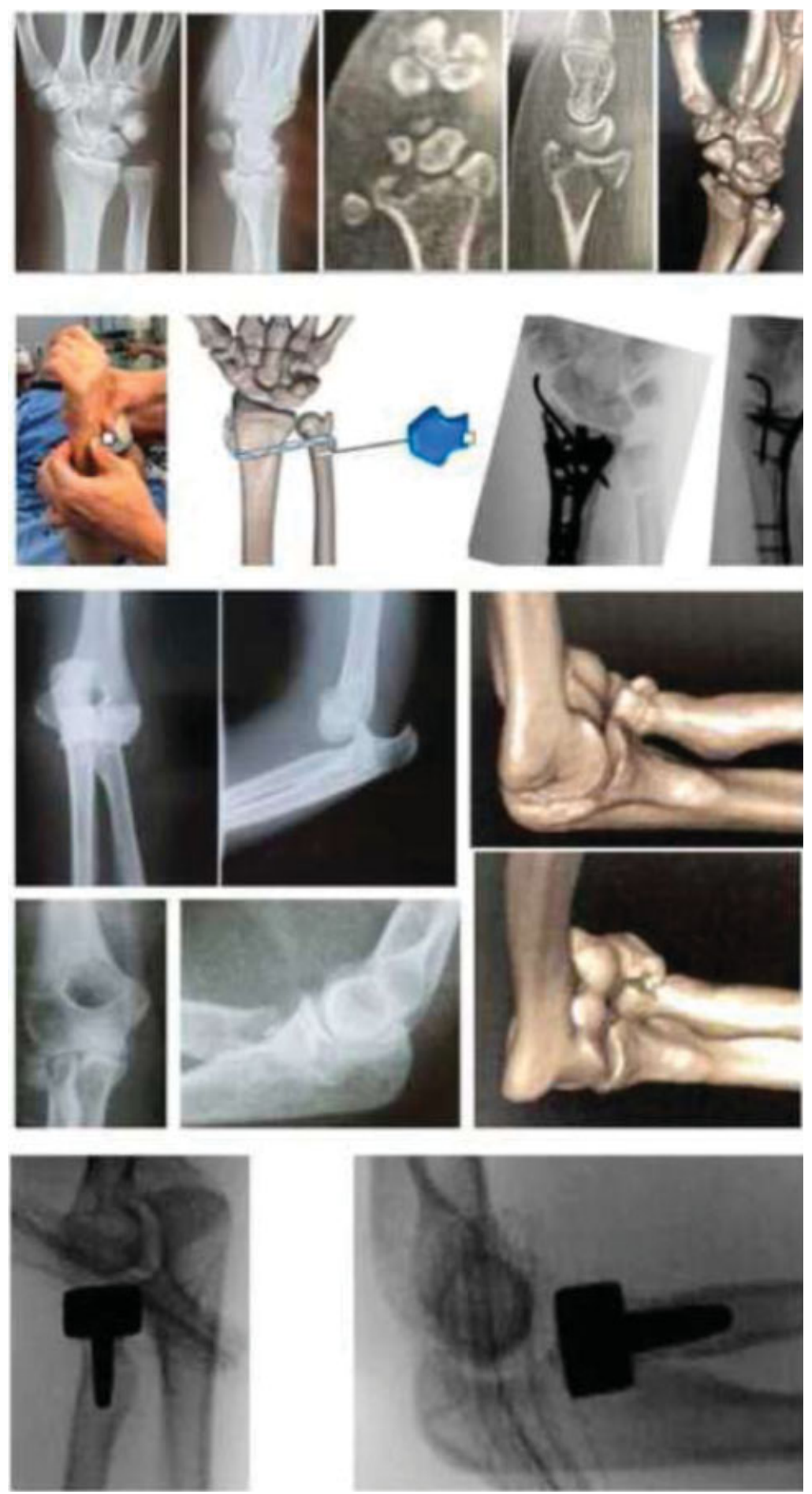

Fig. 10 Pre- and intraoperative aspects: Essex-Lopresti lesion associated with articular DRF - surgical treatment assisted by arthroscopy.
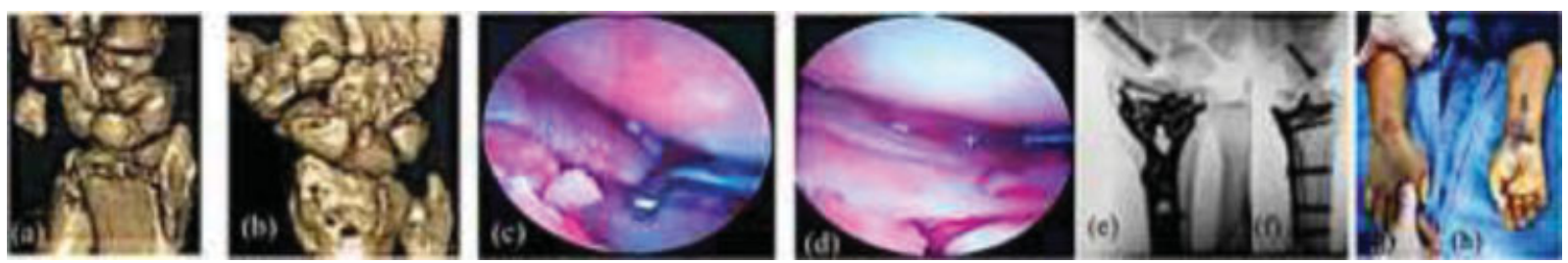

Fig. 11 Pre- and intra operative aspects: $(A, B)$ fracture of the distal radius articular complex associated with scaphoid fracture and scapholunate ligament lesion - surgical treatment assisted by arthroscopy; (C,D) a minimally-invasive volar plate/HCS fixation (E,F). Post-operative radiographic and clinical aspects $(\mathrm{G}, \mathrm{H})$. 


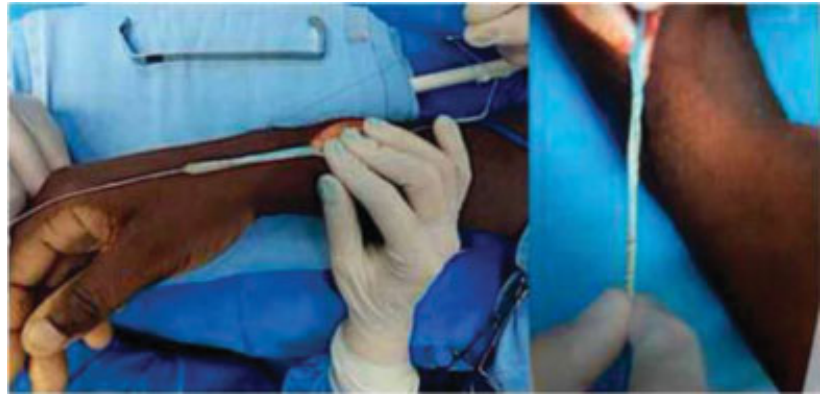

Fig. 12 Intraoperative aspects: InternalBrace in brachioradialis tendon graft.

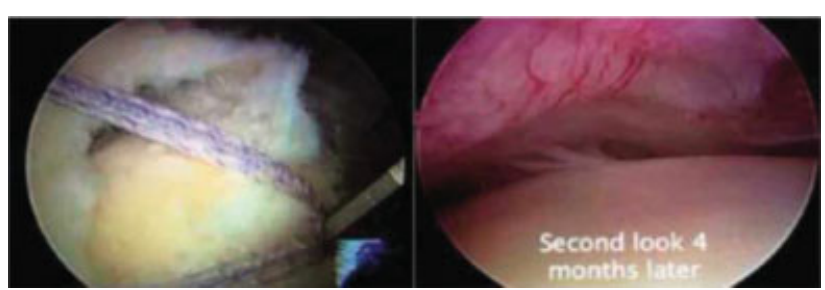

Fig. 13 Intraoperative and second-look images - knee arthroscopy: ligamentization. ${ }^{25}$
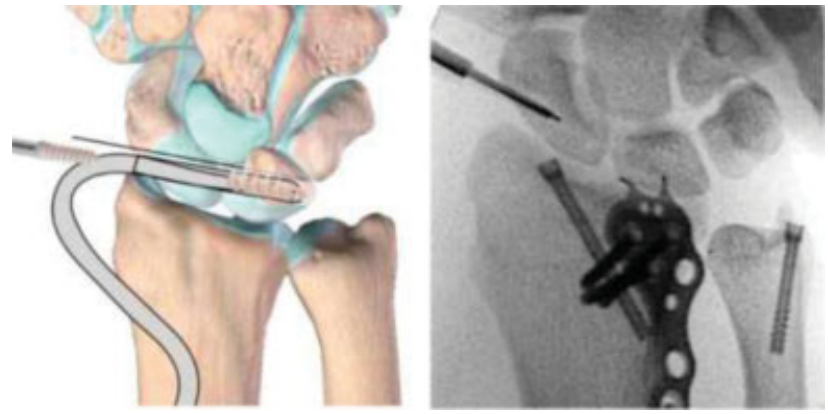

Fig. 15 Schematic procedure for SLL indirect repair (Interna/Brace): All arthroscopy and intraoperative fluoroscopy procedures showed bone tunnels and the DRF treated with dorsal hook plate for fixation of the ulnar dorsal lip and two HCSs for radial/ulnar styloid fractures.

(range: 1 to 12 ). The mean score on the VAS was of 1.66 (range: (1 to 3). There were complications in 2 (13.33\%) of the patients, including extensor tendon synovitis in 1 patient, and a limitation in ROM (stiffness) in the other patient; both were treated with wrist arthroscopy release. The mean time until the return to work was of 6.4 weeks. The present study describes the intraoperative arthroscopic findings, a new classification (-Fig. 6), the treatment algorithm used

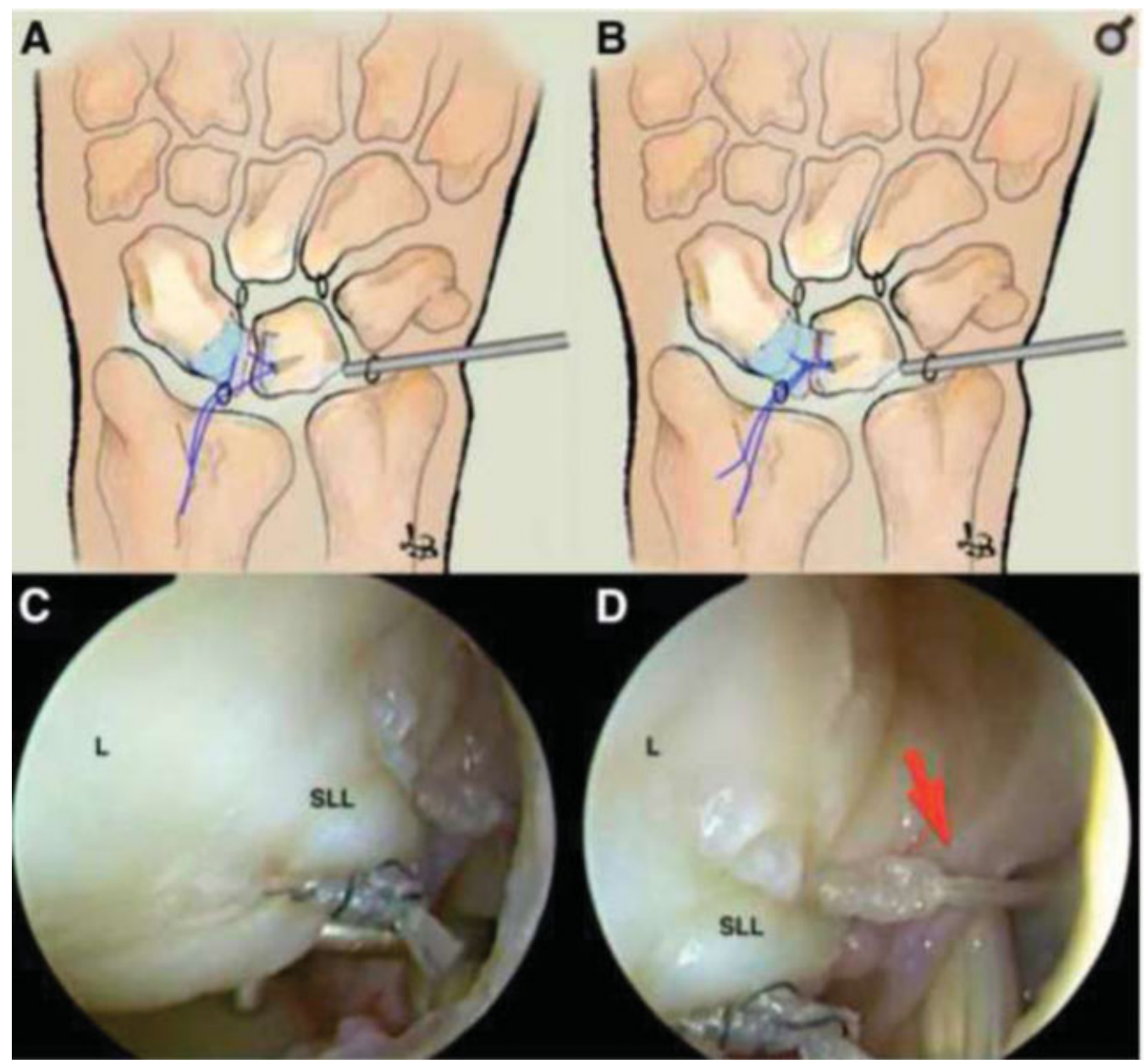

Fig. $14(A, B)$ Direct repair with anchor through the scapholunate ligament (SLL), with the sutures tied and uncut. (C,D) The arthroscope is in the $6 R$ portal. Complete repair of the SLL tear is shown in a left wrist. ${ }^{18}$ 


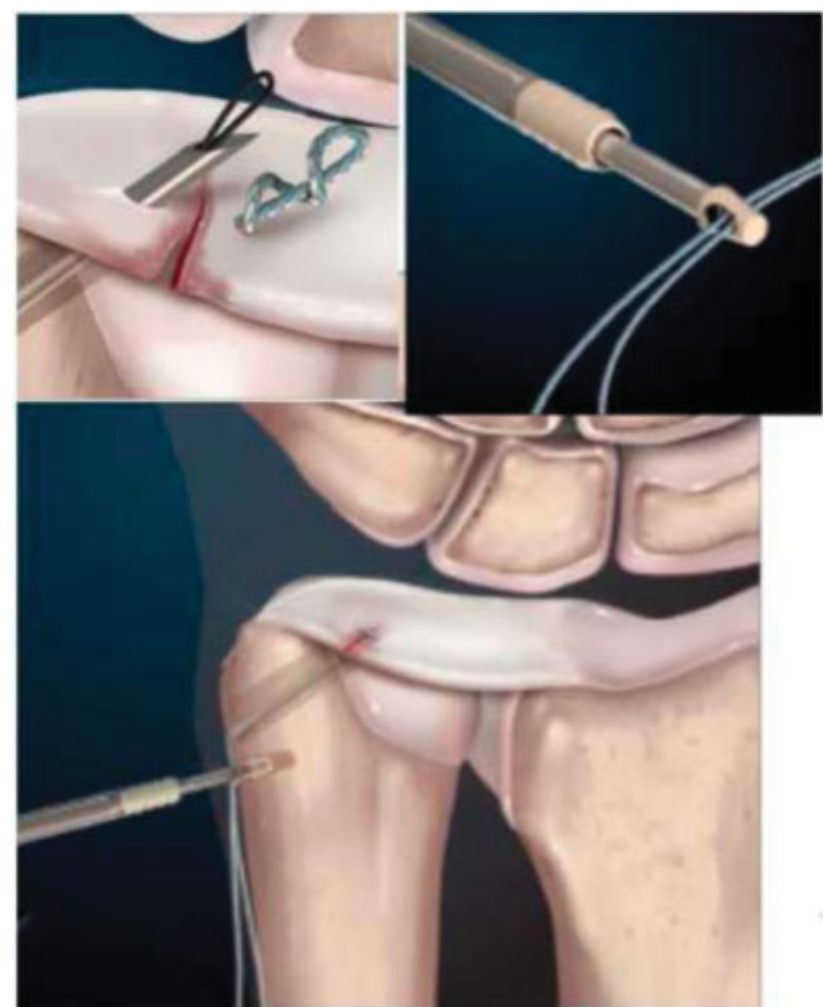

Fig.16 Foveal reinsertion of the triangular fibrocartilage complex (TFCC) with anchor. ${ }^{20}$

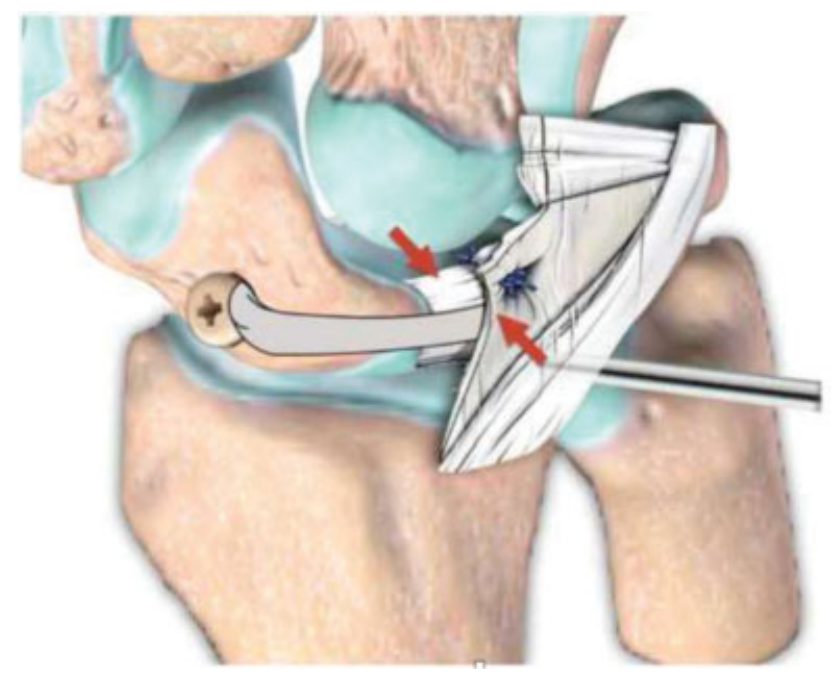

Fig. 17 Schematic SLL indirect repair (Interna/Brace) associated with wrist dorsal capsulodesis: scapholunate axis method ${ }^{19}$ and procedure by Mathoulin et al. ${ }^{21}$
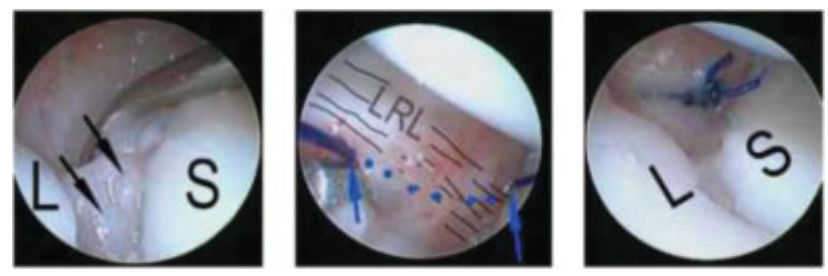

Fig. 18 Wrist palmar capsulodesis - scapholunate lesion (volar portion) $)^{22}$ L, lunate; LRL, long radiolunate; S, scaphoid.
( Fig. 7, - Tables 2,3), and the clinical and functional results of the patients ( - Table $\mathbf{1}$ ).

\section{Discussion}

Scientific studies ${ }^{10}$ claim that the lack of anatomical restoration and on-going osteoarthritis might be associated with the clinical outcome after DRFs. Contrary to this belief, the reduction assisted by arthroscopy in DRFs could be conducted simply and with minimal consumption of resources in the operating room. The proposed technique combines the benefits of rigid fixation with volar locking plates (for the extra-articular component), arthroscopic reduction control, and associated ligament injuries (for the articular component). It is important that the operation is performed using the dry arthroscopic technique. ${ }^{15}$ Perilunate injuries, not displaced, ${ }^{13}$ were recently described, and we proposed a new arthroscopic classification for articular DRFs associated with PLINDs.

In the last three years, a new treatment (repair) for ligament injuries, using InternalBrace as an augmentation, has been developed (-Fig. 12). This treatment enabled a new focus on the restoration of the normal anatomy and function of the traumatized joint. It supports the early mobilization of the repaired ligament and enables the natural tissues to be strengthened and recover progressively with minimal surgical morbidity. Reconstruction only should be indicated if the tissues did not heal properly after augmentation and ligament repair. ${ }^{24}$

These injuries were also treated with ligament reconstruction with a tendon graft (non-vascularized tissue) and bone tunnels, and this graft, which was termed ligamentization (-Fig.13), enabled the clinical and functional recovery of the joint. $^{25,26}$ The rehabilitation protocol included the use of static orthosis in the first two weeks, with proprioception and "dart-throwing motion" exercises since the first day after surgery. ${ }^{27}$ Around the third week, active kinesiotherapy exercises were started, and dynamic orthoses were also used.

\section{The Advantages of Using Wrist Arthroscopy are:}

- Preservation of the mechanisms of proprioception on the wrist (dorsal capsule); ${ }^{28}$

- accurate diagnosis of associated injuries;

- it favors more anatomical ligament repairs and reconstruction; ${ }^{29}$ and

- it enables direct visualization of the reduction of the articular surface.

\section{The Disadvantages are:}

- Higher cost;

- long learning curve; and

- greater difficulty in the integration of fluoroscopy and arthroscopy.

Sufficient stability, joint congruence, and anatomical reduction of the fractures remain the main goals of the treatment. The best result appeared when early joint mobility was allowed, and the patients were allowed to return to their personal and professional activities. Minimally-invasive 
Table 1 Objective and patient-reported outcomes after arthroscopy treatment for distal radius articular fractures and associated lesions

\begin{tabular}{|c|c|c|c|c|c|c|c|c|}
\hline Age & Gender & Trauma/injury & VAS & $\begin{array}{l}\text { Quick } \\
\text { DASH }\end{array}$ & $\begin{array}{l}\text { Grip strength } \\
\text { (\% opposite } \\
\text { side) }\end{array}$ & $\begin{array}{l}\text { ROM } \\
\text { (\% } \\
\text { opposite } \\
\text { side) }\end{array}$ & $\begin{array}{l}\text { Return } \\
\text { to work } \\
\text { (weeks) }\end{array}$ & Complications \\
\hline 17 & $\mathrm{~F}$ & Sports (capoeira) & 1 & 1 & 97 & 100 & 6 & - \\
\hline 56 & $\mathrm{~F}$ & Car accident & 1 & 5 & 95 & 100 & 4 & - - \\
\hline 24 & $\mathrm{M}$ & Car iaccident & 1 & 1 & 98 & 100 & 4 & - - \\
\hline 35 & $\mathrm{~F}$ & Fall from skate & 1 & 1 & 97 & 100 & 6 & - \\
\hline 43 & $\mathrm{M}$ & Fall from motorcycle & 2 & 5 & 89 & 88 & 8 & - \\
\hline 51 & $\mathrm{~F}$ & Fall from ladder & 2 & 5 & 91 & 93 & 8 & - \\
\hline 42 & $\mathrm{M}$ & Fall from 3 meters & 3 & 5 & 88 & 86 & 8 & - \\
\hline 43 & M & Fall during soccer & 3 & 12 & 97 & 100 & 2 & $\begin{array}{l}\text { Synovitis extensor } \\
\text { tendons (EDC) }\end{array}$ \\
\hline 28 & M & Fall from motorcycle & 2 & 5 & 89 & 86 & 8 & - \\
\hline 25 & $\mathrm{M}$ & Fall from motorcycle & 1 & 1 & 99 & 100 & 6 & $\begin{array}{l}\text { Stiffness (new arthroscopy } \\
\text { release) }\end{array}$ \\
\hline 31 & $\mathrm{M}$ & Fall from 2.5 meters & 1 & 1 & 100 & 100 & 6 & - \\
\hline 28 & M & Fall from motorcycle & 2 & 5 & 97 & 91 & 6 & - - \\
\hline 26 & $\mathrm{M}$ & Fall from 4 meters & 2 & 5 & 93 & 90 & 10 & - - \\
\hline 50 & $\mathrm{~F}$ & Skiing accident & 1 & 1 & 95 & 99 & 6 & - - \\
\hline 56 & $\mathrm{~F}$ & Fall from ladder & 2 & 1 & 88 & 89 & 8 & - \\
\hline
\end{tabular}

Abbreviations: EDC, extensor digitorum communis; F, female; M, male; QuickDASH, Quick Disabilities of the Arm, Shoulder and Hand; ROM, range of motion; VAS, Visual Analog Scale.

Table 2 Overview of the fracture type, bone ligament fragment, associated lesion and assisted arthroscopic surgical strategy

\begin{tabular}{|l|l|l|l|}
\hline Fracture type & $\begin{array}{l}\text { Bone ligament } \\
\text { fragment }\end{array}$ & Associated lesion & Surgical strategy \\
\hline Compression & Scaphoid fossa & SL & Nail/HCS + graft + SLAM + capsulodesis (see video 1) \\
\hline Compression & Central & SL/LT & Nail or HCS + graft + SLAM + capsulodesis (SL/LT) \\
\hline Compression & Lunate fossa & SL/LT & Nail or HCS + graft + SLAM + capsulodesis (SL/LT) \\
\hline Avulsion & Radial styloid & RSC/RL & HCS or lateral plate + RSC repair or reconstruction \\
\hline Avulsion & Ulnar styloid & TFCC & HCS and/or TFCC repair/reconstruction \\
\hline Avulsion & Radial dorsal lip & RT/capsule & Hook plates/anchors + dorsal capsulodesis + Interna/Brace \\
\hline Avulsion & Radial palmar lip & RL/capsule & Hook plates/anchors + capsulodesis + Interna/Brace \\
\hline Avulsion & Ulnar dorsal lip & SL/capsule & Hook plates/anchors + SLAM + capsulodesis \\
\hline Avulsion & Ulnar volar lip & UC/capsule & Hook plates/anchors + capsulodesis + Interna/Brace \\
\hline Combined & Radial and ulnar styloid & SL/LT/TFCC & $\begin{array}{l}\text { HCS + SLAM + capsulodesis (SL/LT) + TFCC repair or } \\
\text { reconstruction }\end{array}$ \\
\hline Combined & $\begin{array}{l}\text { Radial styloid and } \\
\text { ulnar dorsal lip }\end{array}$ & SL/TFCC/capsule & HCS or lateral plate + TFCC repair or reconstruction \\
\hline Combined & $\begin{array}{l}\text { Articular complex/ } \\
\text { radial head }\end{array}$ & TFCC/DIOM & $\begin{array}{l}\text { Radial head plate/volar plate/DIOM reconstruction } \\
\text { (see video 3) }\end{array}$ \\
\hline
\end{tabular}

Abbreviations: DIOM, distal interosseous membrane; HCS, headless compression screw; LT, lunotriquetrum; RL, radiolunate; RSC, radioscaphocapitate; RT, radiotriquetral; SL, scapholunate; SLAM, scapholunate axis method; TFCC, triangular fibrocartilage complex; UC, ulnocarpal.

techniques, guided by arthroscopy, were the most advantageous way to assist these patients.

The proper treatment of DRFs often involved bone-ligament fragments (avulsion), ligament injuries in other sites, and, radiocarpal or intercarpal instability (PLIND) in the patients. Here, the role of arthroscopy was essential for the diagnosis and treatment of these injuries. The present study suggested techniques for anatomical and biological ligament 


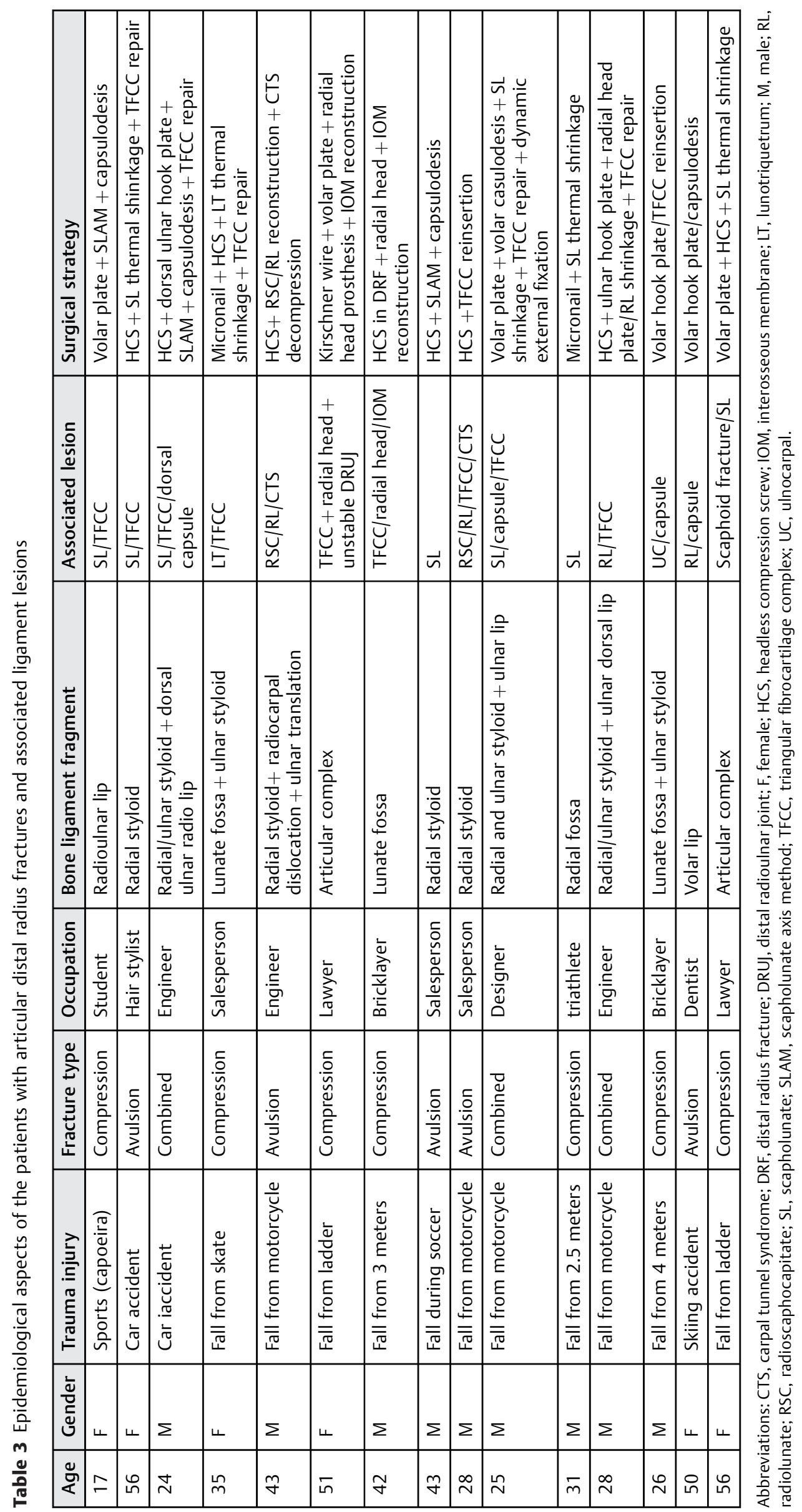


reconstruction and repair. We were able to observe in these patients stable and congruent wrist joints, absence of osteolysis in the bone tunnels, and signs of posttraumatic osteoarthritis. The clinical results and rate of complications in the present study showed the most favorable results compared with the other techniques. ${ }^{10}$ The mean ROM was of $94.80 \%$ on the nonaffected side. The mean score on the QuickDASH was of 3.6 (range: 1 to 12). The mean score on the VAS was of 1.66 (1 to 3 ). Complications were observed in 2 (13.33\%) patients: extensor tendon synovitis in 1 patient, and a limitation in ROM (Stiffness) in another patient; both were treated with wrist arthroscopy release. The mean time until the return to work was of 6.4 weeks.

\section{Author Recommendations}

Many authors have used arthroscopy for the treatment of joint fractures; therefore, the tips and ideas have increased in the existing literature. ${ }^{6,14,15}$ Furthermore, new classifications have appeared, and the procedure becomes increasingly reproducible. The authors would like to stress the importance of university courses with a cadaver laboratory, on going publications, and exchanges of information with colleagues from Europe (Spain, France, Italy), the United States, and Latin America (Brazil, Argentina, Chile, Mexico, and Colombia). Information regarding new treatments for acute articular fractures of the upper limb are lacking, and new studies are required in the future. Most of the available articles were heterogeneous, such as case reports. ${ }^{18,19,21,23,24}$ All of the articles either found or emphasized the role of arthroscopy as the exam/tool that leads to the most favorable diagnoses of fractures and associated injuries. In the treatment of these fractures, reduction guided by arthroscopy was associated with percutaneous fixation, and had sufficient stability to enable immediate mobility. This procedure imparted advantages to the conventional methods of open reduction, primarily by what was involved in the concept of biomechanics and proprioception, as well as the accuracy of joint reduction and respect for the minimal aggression to adjacent tissues.

This surgery required substantial arthroscopic education for the most complicated cases; however, it was easily performed in simple cases. The paradox was that the cases that benefited the most from arthroscopy were the most complex. $^{16}$

\section{Conclusion}

Basic understanding of the essential biomechanic characteristics in DRFs appeared crucial to maintaining the wrist proprioception and achieve sufficient stabilization of the bone ligament fragments and the associated ligament lesions, thereby avoiding secondary dislocation. The present paper provided a management-oriented concept for the diagnosis and treatment of the ligament lesions associated with the stabilization of intra-articular DRFs based on an arthroscopy-assisted procedure through a new classification shown here.

In the treatment of patients with unstable intra-articular DRFs associated with ligament lesions, the ligaments were either repaired or reconstructed, and the fixation of specific bone-ligament fragments was performed through wrist arthroscopy, which proved to be a safe and reliable treatment. Ultimately, the clinical and functional results predicted whether the patients could return to work.

\section{Conflict of Interests}

The authors have no conflict of interests to declare.

\section{References}

1 De Zwart AD, Beeres FJ, Ring D, et al. MRI as a reference standard for suspected scaphoid fractures. $\mathrm{Br} \mathrm{J}$ Radiol 2012;85 (1016):1098-1101

2 Gilley E, Puri SK, Hearns KA, Weiland AJ, Carlson MG. Importance of computed to-mography in determining displacement in scaphoid fractures. J Wrist Surg 2018;7(01):38-42

3 Larribe M, Gay A, Freire V, Bouvier C, Chagnaud C, Souteyrand P. Usefulness of dynamic contrast-enhanced MRI in the evaluation of the viability of acute scaphoid fracture. Skeletal Radiol 2014;43 (12):1697-1703

4 Goffin JS, Liao Q Robertson GAJ. Return to sport following scaphoid fractures: A systematic review and meta-analysis. World J Orthop 2019;10(02):101-114

5 Muller ME, et al. Manual of Internal Fixation, AO-ASIF, 1980. ISBN 3-540-52523-8 3rd ed. 1995

6 Hintringer W, Rosenauer R, Pezzei C, et al. Biomechanical considerations on a CT-based treatment-oriented classification in radius fractures. Arch Orthop Trauma Surg 2020;140(05):595-609

7 Wong K, von Schroeder HP. Delays and poor management of scaphoid fractures: factors contributing to nonunion. J Hand Surg Am 2011;36(09):1471-1474

8 Bain GI, MacLean SBM, McNaughton T, Williams R. Microstructure of the distal radius and its relevance to distal radius fractures. J Wrist Surg 2017;6(04):307-315

9 Short WH, Palmer AK, Werner FW, Murphy DJ. A biomechanical study of distal radial fractures. J Hand Surg Am 1987;12(04): 529-534

10 Gabl M, Arora R, Schmidle G. Biomechanik distaler Radiusfrakturen : Grundlagenverständnis und GPS-Behandlungsstrategie bei winkelstabiler Plattenosteosynthese. Unfallchirurg 2016;119 (09):715-722

11 Goldfarb CA, Rudzki JR, Catalano LW, Hughes M, Borrelli J Jr. Fifteen-year outcome of displaced intra-articular fractures of the distal radius. J Hand Surg Am 2006;31(04):633-639

12 Garcia-Elias M, Puig de la Bellacasa I, Schouten C. Carpal ligaments: a functional classification. Hand Clin 2017;33(03): 511-520

13 Hagert E, Lluch A, Rein S. The role of proprioception and neuromuscular stability in carpal instabilities. J Hand Surg Eur Vol 2016;41(01):94-101

14 Herzberg G. Perilunate injuries, not dislocated (PLIND). J Wrist Surg 2013;2(04):337-345

15 Corella F, Ocampos M, Cerro MD, Larrainzar-Garijo R, Vázquez T. Volar central por-tal in wrist arthroscopy. J Wrist Surg 2016;5 (01):80-90

16 Del Piñal F. Technical tips for (dry) arthroscopic reduction and internal fixation of distal radius fractures. J Hand Surg Am 2011; 36(10):1694-1705 
17 Burn MB, Sarkissian EJ, Yao J. Long-term outcomes for arthroscopy thermal treatment for Scapholunate ligament injuries. J Wrist Surg 2020;9(01):22-28

18 Carratalá V, Lucas FJ, Miranda I, Sánchez Alepuz E, González Jofré C Arthroscopic scapholunate capsule ligamentous repair: suture with dorsal capsular reinforcement for scapholunate ligament lesion. Arthrosc Tech 2017;6(01):e113-e120

19 Yao J, Zlotolow DA, Lee SK. ScaphoLunate Axis Method. J Wrist Surg 2016;5(01):59-66

20 Johnson JC, Pfeiffer FM, Jouret JE, Brogan DM. Biomechanical analysis of capsular re-pair versus arthrex TFCC ulnar tunnel repair for triangular fibrocartilage complex tears. Hand (N Y) 2019;14(04):547-553

21 Mathoulin CL, Dauphin N, Wahegaonkar AL. Arthroscopic dorsal capsuloligamentous repair in chronic scapholunate ligament tears. Hand Clin 2011;27(04):563-572, xi

22 del Piñal F, Studer A, Thams C, Glasberg A. An all-inside technique for arthroscopic suturing of the volar scapholunate ligament. J Hand Surg Am 2011;36(12):2044-2046

23 Carvalho VB, Ferreira CHV, Hoshino AR, Bernardo VA, Ruggiero GM, Aita MA. Dorsal capsulodesis associated with arthoscopyassisted scapholunate ligament reconstruction using a palmaris longus tendon graft. Rev Bras Ortop 2017;52(06): 676-684
24 Aita MA, Alves RS, Ibanez DS, Consoni DAP, de Oliveira RK, Ruggiero GM. Reconstruction of radioscaphocapitate ligament in treatment of ulnar translation. J Wrist Surg 2019;8(02): 147-151

25 Mackay GM, Blyth MJ, Anthony I, Hopper GP, Ribbans WJ. A review of ligament augmentation with the InternalBrace ${ }^{\mathrm{TM}}$ : the surgical principle is described for the lateral ankle ligament and ACL repair in particular, and a comprehensive review of other surgical applications and techniques is presented. Surg Technol Int 2015;26:239-255

26 Sonnery-Cottet B, Freychet B, Murphy CG, Pupim BHB, Thaunat M. Anterior cruciate ligament recon-struction an preservation: the single Anteromedial Bundle Biological Augmentation (SAMBBA) technique. Arthrosc Tech 2014;3(06):e689-e693

27 Dimitris C, Werner FW, Joyce DA, Harley BJ. Force in the scapholunate interosseous lig-ament during active wrist motion. J Hand Surg Am 2015;40(08):1525-1533

28 Hagert E, Garcia-Elias M, Forsgren S, Ljung BO. Immunohistochemical analysis of wrist ligament innervation in relation to their structural composition. J Hand Surg Am 2007;32(01):30-36

29 Aita MA, Mallozi RC, Ozaki W, Ikeuti DH, Consoni DAP, Ruggiero GM. Ligamentous reconstruction of the interosseous membrane of the forearm in the treatment of instability of the distal radioulnar joint. Rev Bras Ortop 2018;53(02):184-191 